\title{
A Facile Method for Controlled Fabrication of Hybrid Silver Nanoparticle-Poly( $\varepsilon$-caprolactone) Fibrous Constructs with Antimicrobial Properties
}

\author{
Sukhwinder K. Bhullar ${ }^{1, *, \dagger}$, Duygu Gazioglu Ruzgar ${ }^{2}$, Giuseppino Fortunato ${ }^{3}$, \\ Ginpreet Kaur Aneja ${ }^{4}$, Mehmet Orhan ${ }^{5}$, Saeed Saber-Samandari ${ }^{6}$, Mojtaba Sadighi ${ }^{7}$, \\ Samad Ahadian ${ }^{8}$, and Murugan Ramalingam ${ }^{9, *}$ \\ ${ }^{1}$ Department of Mechanical Engineering, Bursa Technical University, Bursa 16330, Turkey \\ ${ }^{2}$ Department of Fiber and Polymer Engineering, Bursa Technical University, Bursa 16330, Turkey \\ ${ }^{3}$ Empa, Swiss Federal Laboratories for Materials Science and Technology, Lerchenfeldstrasse, St. Gallen 9014, Switzerland \\ ${ }^{4}$ Department of Pharmaceutical Technology, Shobhaben Pratapbhai Patel School of Pharmacy and Technology Management, \\ SVKM'S NMIMS, Mumbai 400056, India \\ ${ }^{5}$ Department of Textile Engineering, Uludag University, Bursa 16059, Turkey \\ ${ }^{6}$ New Technologies Research Center, Amirkabir University of Technology, Tehran 15875-4413, Iran \\ ${ }^{7}$ Department of Mechanical Engineering, Amirkabir University of Technology, Tehran 15875-4413, Iran \\ ${ }^{8}$ Toronto General Research Institute, University Health Network, Toronto, Ontario M5G 2C4, Canada \\ ${ }^{9}$ Biomaterials and Stem Cell Engineering Lab, Centre for Biomaterials, Cellular and Molecular Theranostics, \\ School of Mechanical Engineering, Vellore Institute of Technology (VIT) (Deemed to be University), Vellore 632014, India
}

\begin{abstract}
Infection is one of the major factors affecting wound healing. The use of polymeric fibrous constructs or scaffolds with encapsulated biologically active components has shown great potential in topical wound care as wound dressings to expedite wound healing process; however, there is a limitation in precise control over the release of active components. Therefore, in this study, the authors developed a facile method for controlled fabrication of poly( $\varepsilon$-caprolactone) (PCL) microfibrous constructs with silver $(\mathrm{Ag})$ nanoparticles as antibacterial agent by single capillary electrospinning. By optimizing spinning parameters, the PCL microfibrous constructs were fabricated. The encapsulation of $\mathrm{Ag}$ nanoparticles within the PCL microfibers was confirmed using microstructural analysis. The encapsulation efficacy and release profile of Ag was evaluated in vitro. The diffusion study further revealed the controlled release and optimal bioavailability of Ag during the experimental period. In vitro assessment of antibacterial activity of electrospun hybrid constructs showed a high antibacterial activity and an inhibitory effect on the growth of both staphylococcus aureus and escherichia coli bacteria when compared to PCL and their efficiency of antibacterial activity also varied with respect to the percent of encapsulated Ag nanoparticles. This kind of Ag nanoparticles-loaded PCL microfibrous constructs may be considered for wound care applications.
\end{abstract}

Keywords: Polymeric Construct, Silver Nanoparticle, Electrospinning, Antimicrobial, Controlled Release, Wound Care.

\section{INTRODUCTION}

Infection is a common problem associated with wounds and skin injuries. Up to $75 \%$ of deaths happen because of severe infection. Wound infection often occurs by the

\footnotetext{
*Authors to whom correspondence should be addressed.

${ }^{\dagger}$ Present address: St. Boniface Hospital, Albrechtsen Research Centre, Winnipeg, MB R2H 2A6, Canada.
}

growth of microorganisms and the most commonly caused by staphylococcus aureus and pseudomonas aeruginosa. ${ }^{1-3}$ The global wound care dressing market is expected to reach $\$ 4.4$ billion by 2019 from $\$ 3.1$ billion in 2012, growing at an average annual rate of $5.7 \%$ from 2012 to $2019 .{ }^{4}$ The statistical data suggest that wound care market forms a large sector of total biomedical market. However, there are still many problems that health care professionals are 
currently encountering with rising number of patients suffering from microbial infections and injuries related to wounds and burns.

Bacteria, fungi, and parasites often cause skin infection on the human body. Among them, staphylococcus aureus and trichophyton rubrum are the most common pathogens that are responsible for skin and nail infections. ${ }^{5}$ Some wounds and burns damage the underlying tissues or organs, such as bone, muscle, tendon, arteries, and nerves, which are deeper and need medical attention to prevent infection and loss of function. ${ }^{6}$ There are many ointments, topical gels, and creams available in the market for the treatment of microbial infection and wound healing, but the most common disadvantage of these treatments is the easy washing out of the medicament from the site, which ultimately results in failure of therapeutic activity. ${ }^{7}$ In addition, patient compliance also is a matter, which results in therapeutic failure. Hence, there is a need to develop biomaterial-based systems, such as polymeric scaffolds encapsulating therapeutic drugs, which are able to stay on the wound area providing continuous release of drugs with desired therapeutic activity.

One of the known therapeutic agents to prevent infection is silver (Ag), which has widely been used in wound dressings. Ag has an excellent antimicrobial with broad-spectrum activity on gram-positive, gram-negative bacteria, and fungal strains. ${ }^{8-11}$ Therefore, Ag is being considered as an excellent antimicrobial candidate in wound healing and burn management. ${ }^{12-14}$ However, effect of $\mathrm{Ag}$ concentration and its releasing profile have less been studied in the context of electrospun fibrous constructs. Electrospinning is a simple and versatile method for fabrication of polymeric fibrous constructs, with or without the incorporation of biologically active agents, for various biomedical applications, including wound dressing. ${ }^{15-20}$ Poly $(\varepsilon$-caprolactone) (PCL) is a semicrystalline aliphatic polyester that has been widely used in various biomedical applications. ${ }^{21-23}$ Therefore, in this study, the authors have made an attempt to develop a facile method for controlled fabrication of PCL microfibrous constructs with Ag nanoparticles by single capillary electrospinning. The effect of $\mathrm{Ag}$ concentration encapsulated into the PCL microfibers, their diffusion/release profiles, and their antimicrobial activities have been systematically investigated.

\section{MATERIAL AND METHODS}

\subsection{Electrospinning of Ag-Encapsulated PCL Constructs}

PCL with 80000 Da molecular weight (Sigma, USA), chloroform, methanol, and Ag nanoparticles $(\sim 100 \mathrm{~nm}$ diameter) were used as received. The PCL was dissolved in the mixture of chloroform/methanol at a volume ratio of 7:1. Ag nanoparticles at concentrations of $15 \%, 10 \%$ and $5 \%(\mathrm{w} / \mathrm{w})$ were blended with PCL as detailed in Table I.
Table I. Composition of samples in this work.

\begin{tabular}{lc}
\hline Sample no. & Composition \\
\hline Sample 1 & PCL \\
Sample 2 & PCL $+15 \%$ Ag nanoparticles \\
Sample 3 & PCL $+10 \%$ Ag nanoparticles \\
Sample 4 & PCL $+5 \%$ Ag nanoparticles \\
\hline
\end{tabular}

The solutions were then stirred overnight at 1,100 rpm at room temperature. Each of PCL-Ag nanoparticles blended solution was loaded into a $10 \mathrm{~mL}$ syringe with $14.43 \mathrm{~mm}$ inner diameter and the solution was pumped at a constant rate $(0.25 \mathrm{~mL} / \mathrm{m})$ via a syringe pump at distance of $15 \mathrm{~cm}$ from the needle tip. An electric voltage $(15 \mathrm{kV})$ was applied from a high voltage power supply to fabricate thick microfibrous constructs on aluminum foil. The schematic representation of the electrospinning process is shown in Figure 1.

\subsection{Fourier Transform Infrared (FT-IR) Analysis}

Chemical functional groups of electrospun polymeric constructs were characterized using a FT-IR spectrophotometer (Thermo Scientific ${ }^{\mathrm{TM}}$ Nicolet iS50, USA) over ATR mode in the range between 4000 and $400 \mathrm{~cm}^{-1}$ at $2 \mathrm{~cm}^{-1}$ resolution with an average of 100 scans.

\subsection{Contact Angle Measurement}

Contact angle of water on electrospun polymeric constructs was measured according to sessile drop method using a tensiometer (Attension Theta Lite, Finland). For this purpose, $4 \mu \mathrm{l}$ of distilled water droplet was dropped onto the surface of constructs using a syringe. At least four drops were placed on each surface and photographed to measure the contact angle values.

\subsection{Scanning Electron Microscopy (SEM)}

The structural morphology of electrospun polymeric costructs was studied using a SEM (ZEISS EVO 40XVP) with an accelerating voltage of $15 \mathrm{kV}$. The constructs were coated with gold using a sputter coater (BAL-TEC

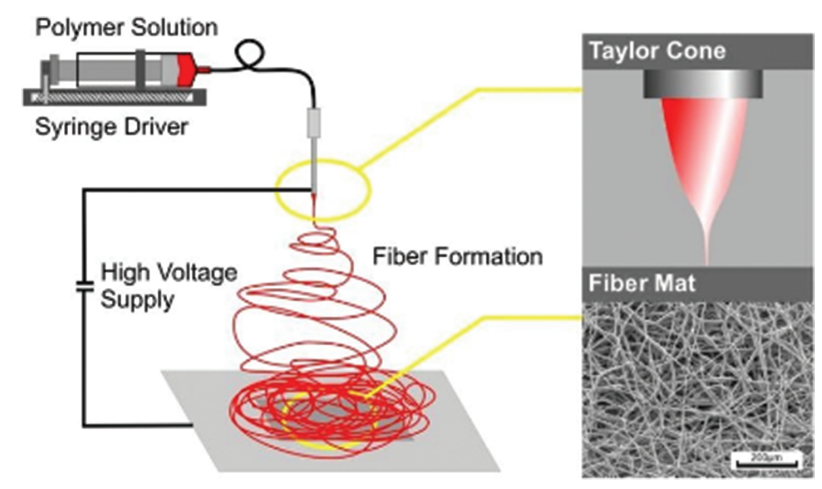

Figure 1. Schematic illustration of electrospinning process to fabricate PCL-Ag microfibers. 
SCD005) before the observation. The diameter of fibers was measured from the SEM micrographs using an image analysis software (Image J, National Institutes of Health, USA).

\subsection{X-ray Photoelectron Spectroscopy (XPS)}

XPS measurements on electrospun polymeric constructs were performed using a SCIENCE SES 2002 instrument. This analysis method postulates the energy distribution of electrons emitted as a result of interaction between the material and incident X-rays allowing us to determine the existence of $\mathrm{Ag}$ nanoparticles in PCL fibrous constructs. The experiments were carried out in an ultra-high-vacuum system with a base pressure of about $6 \times 10^{-10} \mathrm{~Pa}$. The XPS spectra were recorded in normal emission mode and evaluated.

\subsection{Diffusion Study}

In vitro $\mathrm{Ag}$ release of microfibrous scaffolds were studied using a dialysis membrane consisted of two chambers, the donor and the receptor compartments. The receptor compartment was maintained at $37 \pm 10{ }^{\circ} \mathrm{C}$ by means of placing the assembly with an arrangement for water circulation on magnetic stirrer. The receiving compartment was filled with $20 \mathrm{~mL}$ of the phosphate buffer $(\mathrm{pH}=6.8)$ and was continuously stirred at $100 \mathrm{rpm}$ by means of magnetic stirrer. The donor compartment and the sampling port were sealed with paraffin. Aliquots were remoyed from the receptor compartment for 41 days.

\subsection{Antibacterial Activity of Ag}

Microfibrous scaffolds were tested against two microorganisms; Escherichia coli (ATCC 35218, Gram-negative bacteria) and Staphylococcus aureus (ATCC 6853, Grampositive bacteria). The antibacterial efficacies of the samples were quantitatively evaluated with ASTM 2149 Standard Dynamic Contact Conditions test method. In this test, the suspension of bacteria was prepared in nutrient broth and a standardized concentration of about
Table II. Characteristic infrared bands of PCL-Ag samples.

\begin{tabular}{lc}
\hline Position $\left(\mathrm{cm}^{-1}\right)$ & Vibrator \\
\hline 2945 & Asymmetric $\mathrm{CH}_{2}$ stretching \\
2865 & Symmetric $\mathrm{CH}_{2}$ stretching \\
1720 & Carbonyl stretching \\
1294 & $\mathrm{C}-\mathrm{O}$ and $\mathrm{C}-\mathrm{C}$ stretching in the crystalline phase \\
1240 & Asymmetric COC stretching \\
1165 & Symmetric COC stretching \\
\hline
\end{tabular}

$10^{6} \mathrm{cfu} / \mathrm{mL}$ was exposed to samples for the antibacterial testing. All samples were incubated at $37{ }^{\circ} \mathrm{C}$ and shaken in a wrist-action shaker for 24 hours. Serial dilutions were prepared and plated on Muller-Hinton II agar plate. After incubation, bacteria colonies of each plate were counted and reduction in bacteria population was calculated according to the equation below;

$$
\text { Reduction }(\%),(\mathrm{CFU} / \mathrm{mL})=\left(\frac{B-A}{B}\right) * 100
$$

where $A$ is the number of bacteria recovered from the inoculated treated sample in the jar incubated for 24 hours and $B$ is the number of bacteria recovered from the inoculated treated sample at ' 0 ' contact time. The peptone water without any sample was used as the control sample and treated in the same manner.

\section{RESULTS AND DISCUSSION}

By optimizing the electrospinning parameters, PCL and Ag nanoparticles-loaded PCL microfibrous constructs were fabricated. The physicochemical properties and antimicrobial activity of the electrospun hybrid constructs have been assessed.

\subsection{FTIR}

A transmission spectrum of neat PCL microfibers was given in the $400-4000 \mathrm{~cm}^{-1}$ region in Figure 2. Also, it can be seen that Ag nanoparticle did not make any significant difference in the peak values in the spectrum. According to the spectrum (Fig. 2), asymmetric and symmetric

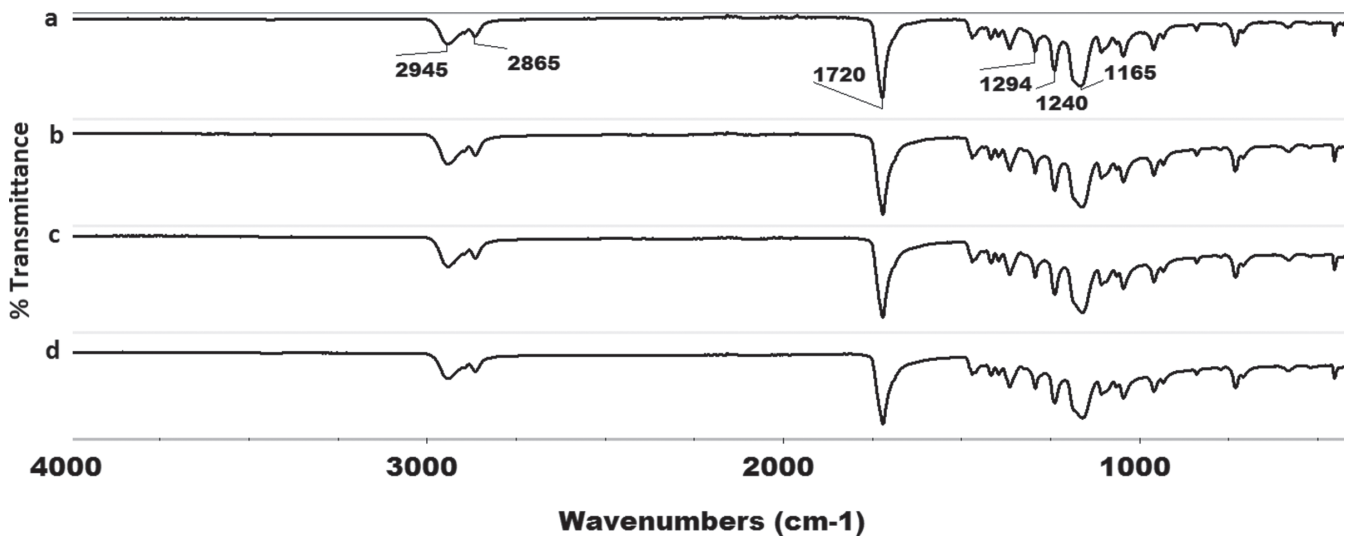

Figure 2. Infrared spectrum of PCL microfibers including sample 1 (a), sample 2 (b), sample 3 (c), and sample 4 (d). 


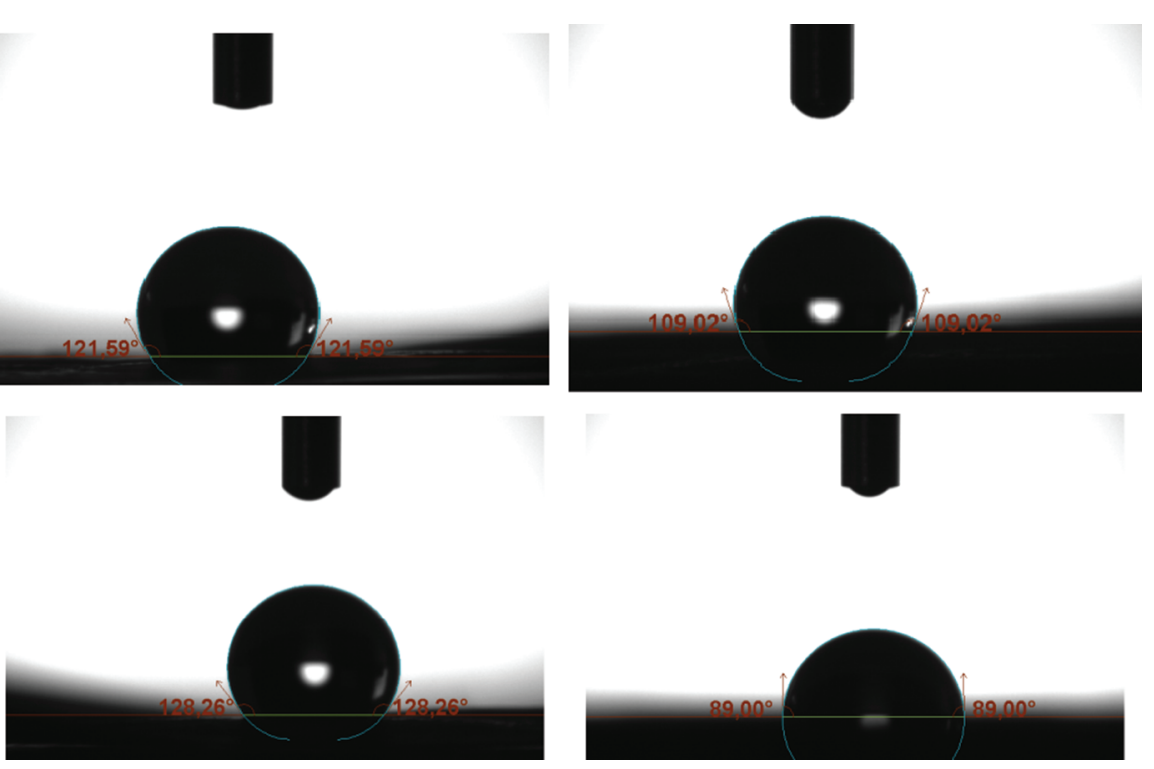

Figure 3. Micrographs on water contact angle on PCL and PCL-Ag samples.

Table III. Hydrophobic activity of PCL-Ag microfibers according to the contact angle measurements.

\begin{tabular}{ccccc}
\hline & Sample 1 & Sample 2 & Sample 3 & Sample 4 \\
\hline $\begin{array}{c}\text { Water contact } \\
\text { angle (deg.) }\end{array}$ & 121.59 & 109.02 & 128.26 & 89 \\
\hline
\end{tabular}

C-H stretching vibrations of PCL microfibers appeared at the peaks of $2945 \mathrm{~cm}^{-1}$ and $2865 \mathrm{~cm}^{-1}$ confirming the presence of $\mathrm{CH}_{2}$ groups. ${ }^{24}$ Also, carbonyl stretching peak around $1720 \mathrm{~cm}^{-1}$ can be identified from the spectrum. The band at $1294 \mathrm{~cm}^{-1}$ is assigned to the backbone $\mathrm{C}-\mathrm{C}$ and $\mathrm{C}-\mathrm{O}$ stretching modes in the crystalline

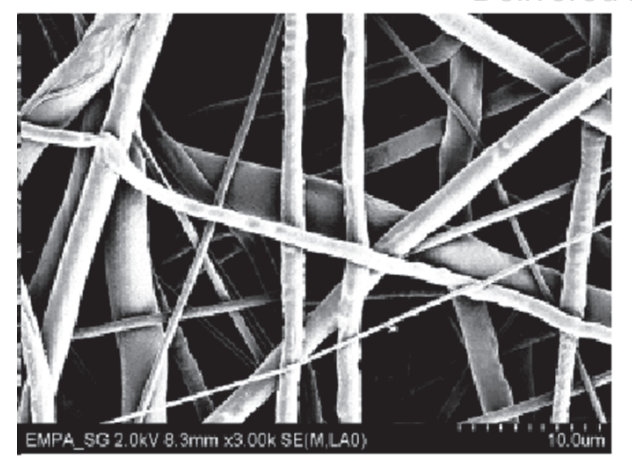

(a)

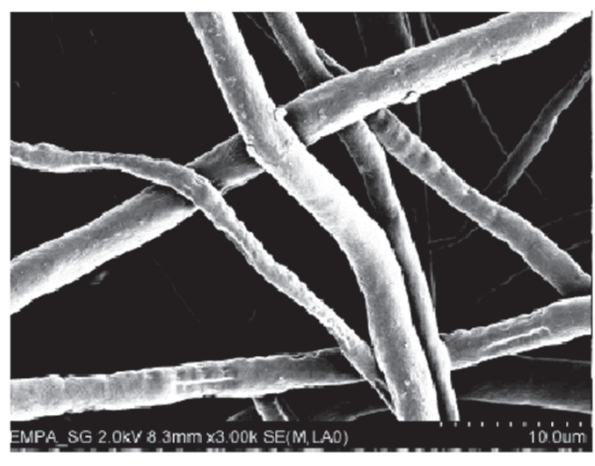

(c)

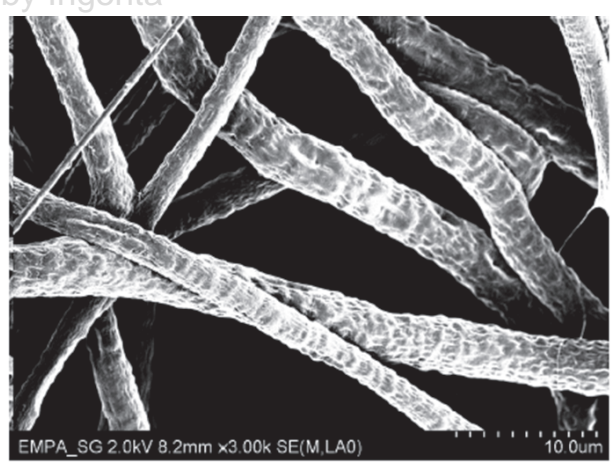

(b)

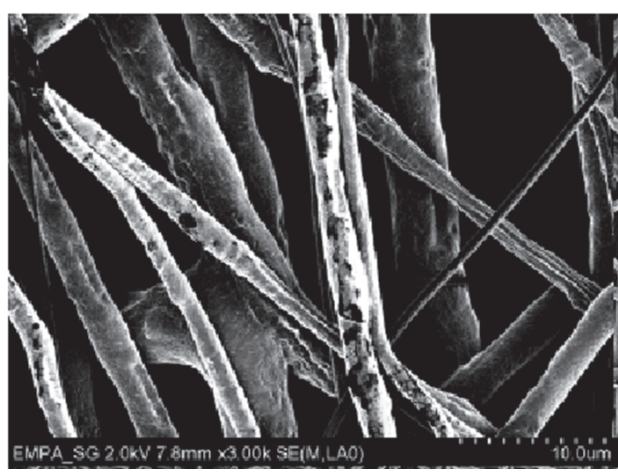

(d)

Figure 4. SEM pictures of PCL microfibers ranging from sample 1 (a), sample 2 (b), sample 3 (c), to sample 4 (d). 
Table IV. Surface elemental concentration results of samples measured by XPS.

\begin{tabular}{llllllrr}
\hline \multicolumn{7}{c}{ C1 $s=$ carbon, } \\
O1 $s=$ Oxygen & Position & FWHM & R.S.F. & Area & $\%$ & At.Conc. \\
\hline \multirow{2}{*}{ Sample 1} & C $1 s$ & 285.13 & 3.111 & 1 & 230.82 & 99.51 \\
& O $1 s$ & 532.33 & 3.16 & 137.62 & 157.78 & 0.49 \\
Sample 2 & C $1 s$ & 284.68 & 2.98 & 1 & 256.51 & 99.55 \\
& O $1 s$ & 531.88 & 3.192 & 137.62 & 159.99 & 0.45 \\
Sample 3 & C $1 s$ & 284.8 & 2.643 & 1 & 346.62 & 99.81 \\
& O $1 s$ & 532.8 & 3.358 & 137.62 & 92.53 & 0.19 \\
Sample 4 & C $1 s$ & 284.89 & 2.705 & 1 & 328.61 & 99.82 \\
& O $1 s$ & 532.89 & 3.248 & 137.622 & 82.16 & 0.18 \\
\hline
\end{tabular}

Table V. Maximum amount of Ag in the samples.

\begin{tabular}{lccccc}
\hline & $\begin{array}{c}\text { Amount Ag } \\
{[\text { wt.\% }]}\end{array}$ & Decimal & $\begin{array}{c}\text { Ag weight } \\
{[\mathrm{g}]}\end{array}$ & $\begin{array}{c}\text { Ag weight } \\
{[\mu \mathrm{g}]}\end{array}$ & $\mu \mathrm{g} / \mathrm{ml} \mathrm{Ag}$ \\
\hline Sample 1 & 0 & 0 & 0 & 0 & 0 \\
Sample 2 & 15 & 0.15 & 0.003375 & 3375 & 675 \\
Sample 3 & 10 & 0.10 & 0.002170 & 2170 & 434 \\
Sample 4 & 5 & 0.05 & 0.001075 & 1075 & 215 \\
\hline
\end{tabular}

PCL. ${ }^{25}$ The strongest band and their assignments are given in Table II. These results indicate that the presence of $\mathrm{Ag}$ nanoparticles up to $15 \%$ did not significantly affect the molecular components and structure of PCL.

\subsection{Water Contact Angle Measurements}

Contact angle of water on the samples measured with a surface-analysis instrument is given in Figure 3. In wettability studies, the measurement of contact angles is often considered as the primary data to investigate the degree of wetting when a solid and liquid interact. Small contact angles $\left(<<90^{\circ}\right)$ correspond to high wettability, while large contact angles $\left(>>90^{\circ}\right)$ correspond to low wettability. ${ }^{26}$ The hydrophobic behavior of PCL was changed as Ag nanoparticles were added to the polymer (Table III). However, there was no obvious trend as a result of adding Ag nanoparticles to the PCL. The Ag nanoparticles changed both roughness and hydrophobicity of PCL and these parameters were effective on the contact angle measurements.

\subsection{SEM Results}

Figure 4 shows the SEM micrographs PCL and PCLAg samples and it is clearly observed that the electrospun hybrid constructs are made up of microfibers. The

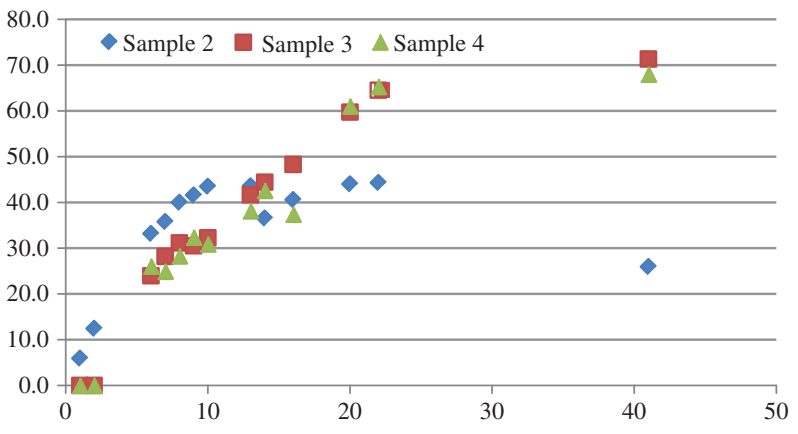

Figure 5. Ag release (\%) versus time for underlying samples.

measured average fiber diameters for sample 1 to sample 4 are 2, 3.6, 2.6, and $2.25 \mu \mathrm{m}$, respectively. These results showed the formation of microfibers in all samples and there was no significant difference in the fiber diameter among the samples tested.

\subsection{Surface Elemental Concentration}

Surface elemental concentration for all samples was measured using XPS as shown in Table IV. No Ag nanoparticles were noticed at the surface $(10 \mathrm{~nm}$ depth), which proves that the Ag nanoparticles were encapsulated within the fibers. Therefore, it is expected that the Ag nanoparticles would be able to have a sustained release over long time.

\subsection{Diffusion Study}

The in vitro Ag release from the samples was studied using diffusion cell and aliquots were removed from the receptor compartment over 41 days of culture. The samples were analyzed spectrophotometrically at $254 \mathrm{~nm}$. The release of $\mathrm{Ag}$ nanoparticles was calculated from standard calibration curve as shown in Tables V, VI, and Figure 5.

The in vitro diffusion results showed significant Ag permeation across the dialysis membrane. The PCL films loaded with $5 \%, 10 \%$, and $15 \% \mathrm{Ag}$ nanoparticles resulted in $68 \%, 71.3 \%$, and $26 \% \mathrm{Ag}$ release, respectively. These results confirm the biodegradation of PCL samples over time and sustained Ag release from them. The PCL plays a significant role as the scaffold for $\mathrm{Ag}$ nanoparticles and avoids the burst release of Ag nanoparticles.

\subsection{Antibacterial Activity of Ag}

Antibacterial activity of Ag nanoparticles determined by ASTM 2149 test method are shown in Tables VII, VIII,

Table VI. Percentage of Ag release [\%].

\begin{tabular}{lcccccccccccccc}
\hline Days & 1 & 2 & 6 & 7 & 8 & 9 & 10 & 13 & 14 & 16 & 20 & 22 & 41 \\
\hline Sample 1 & 0 & 0 & 0 & 0 & 0 & 0 & 0 & 0 & 0 & 0 & 0 \\
Sample 2 & 5.9 & 12.4 & 33.2 & 35.8 & 40.0 & 41.6 & 43.5 & 40.2 & 36.6 & 40.6 & 44.0 & 44.3 & 26.0 \\
Sample 3 & 0.0 & 0.0 & 24.0 & 28.2 & 31.2 & 30.5 & 32.3 & 41.7 & 44.4 & 48.3 & 59.7 & 64.5 & 71.3 \\
Sample 4 & 0.0 & 0.0 & 26.0 & 24.9 & 28.3 & 32.4 & 30.9 & 38.1 & 42.6 & 37.4 & 61.0 & 65.3 & 68.0 \\
\hline
\end{tabular}


Table VII. Antibacterial activities against $S$. aureus. $^{a}$

\begin{tabular}{lcc}
\hline & \multicolumn{2}{c}{ Antibacterial activity after 24 hours } \\
\cline { 2 - 3 } & $\%$ & $\log$ \\
\hline Sample 1 & -94.71 & -1.28 \\
Sample 2 & -100.00 & -6.15 \\
Sample 3 & -100.00 & -6.15 \\
Sample 4 & -100.00 & -6.15 \\
\hline
\end{tabular}

Note: ${ }^{a}$ The concentration of bacteria was adjusted to $1.41 \times 10^{6}(\log 6,15) \mathrm{cfu}^{*} / \mathrm{mL}$ for each sample.

Table VIII. Antibacterial activity of samples against E. coli. $^{a}$

\begin{tabular}{lrr}
\hline & \multicolumn{2}{c}{ Antibacterial activity after 24 hours } \\
\cline { 2 - 3 } & \multicolumn{1}{c}{$\%$} & $\log$ \\
\hline Sample 1 & 36.67 & 0.14 \\
Sample 2 & -100.00 & -6.13 \\
Sample 3 & -100.00 & -6.13 \\
Sample 4 & -100.00 & -6.13 \\
\hline
\end{tabular}

Note: ${ }^{a}$ The concentration of bacteria was adjusted to $1.36 \times 10^{6}(\log 6,13) \mathrm{cfu}^{*} / \mathrm{mL}$ for each sample.

and Figures 6 and 7. According to the test results, the PCL surface, which contained no Ag nanoparticles exhibited moderate biocidal activities (-94.71\%) against $S$. aureus. On the other hand, the addition of Ag nanoparticles even at the lowest concentration (5\%) into PCL showed a significant antibacterial activity $(-100 \%)$. Similar results were obtained with the test conducted against the Gram-negative bacteria. As shown in Table VIII, PCL surface without Ag nanoparticles exhibited no antibacterial activities (36.67\%) against $E$. coli. The antibacterial activities were dramatically increased (from $36.67 \%$ to $-100 \%$ ) after combining Ag nanoparticles with PCL.

Note: The positive values of bacterial reduction (\%) demonstrate an increase in the bacterial growth, while the negative values of bacterial reduction $(\%)$ demonstrate a decrease in the bacterial growth. The value of $(-) 100 \%$ indicates that all bacteria on the surface were killed.

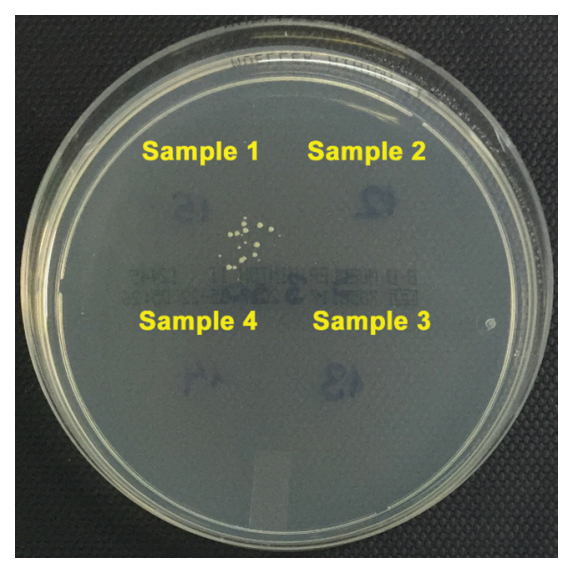

Figure 6. Antibacterial activity of samples against S. aureus.

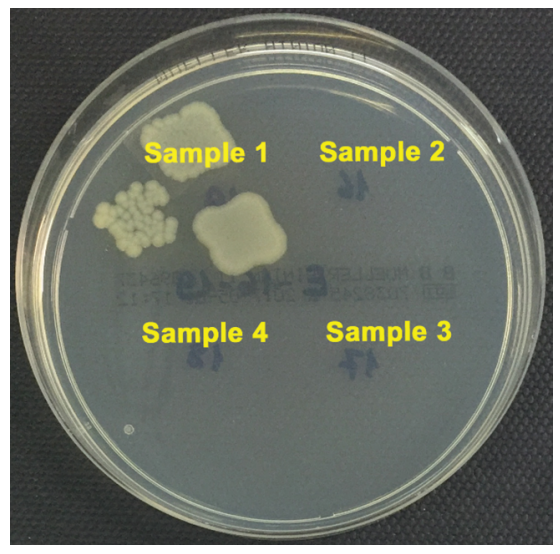

Figure 7. Antibacterial activity of samples against E. coli.

\section{CONCLUSIONS}

A facile method has been developed for controlled fabrication of PCL microfibrous constructs with/without Ag nanoparticles by single capillary electrospinning. The encapsulation of Ag nanoparticles within the PCL microfibers was confirmed using microstructural analysis. Furthermore, the surface elemental concentration results measured by XPS showed that there was no $\mathrm{Ag}$ at the surface of films. Therefore, Ag was successfully encapsulated within the fibers, which supports a sustained release of $\mathrm{Ag}$ from the microfibers. The in vitro diffusion study clearly exhibited controlled release of Ag nanoparticles from the hybrid constructs. Also, the in vitro assessment of antibacterial activity of electrospun hybrid constructs demonstrated a high antibacterial activity and an inhibitory effect on the growth of both staphylococcus aureus and escherichia coli bacteria, which further encourages their application as wound dressing material.

\section{References and Notes}

1. D. Church, S. Elsayed, O. Reid, B. Winston, and R. Lindsay, Clin. Microbiol. Rev. 19, 403 (2006).

2. J. L. Macedo and J. B. Santos, Mem. Inst. Oswaldo. Cruz. 100, 535 (2005).

3. H. Vindenes and R. Bjerknes, Burns 21, 575 (1995).

4. G. Dabiri, D. Heiner, and V. Falanga, Expert Opin. Emerg. Drugs 18, 405 (2013).

5. D. P. Orgill and C. Blanco, Biomaterials for Treating Skin Loss, Woodhead Publishing, Cambridge, UK (2009).

6. A. R. Siddiqui and J. M. Bernstein, Clin. Dermatol. 28, 519 (2010).

7. H. M. Powell, D. M. Supp, and S. T. Boyce, Biomaterials 29, 834 (2008).

8. T. C. Dakal, A. Kumar, R. S. Majumdar, and V. Yadav, Front. Microbiol. 7, 1831 (2016).

9. G. S. M. Isabel, P. Stefano, T. Giacomo, G. M. Nathanael, H. Karl, L. C. Enrique, and P. Polina, Mater. Sci. Eng. C 50, 332 (2015).

10. W. Xiaoxiao, Z. Yudong, W. Jian, Y. Lina, W. Cai, L. Jiabin, W. Zhigu, and W. Kaisheng, Prog. Natural Sci. Mater. Inter. 25, 197 (2015).

11. S. Massand, F. Cheema, S. Brown, W. J. Davis, B. Burkey, and P. M. Glat, J. Wound Care 26, 26 (2017).

12. G. Amin, A. Ludwig Erik, B. A. Rohan, L. Soo-Hyoung, P. Chan Hee, and K. C. Sang, Colloids Inter. Sci. Comm. 6, 5 (2015).

\section{J. Nanosci. Nanotechnol. 19, 6949-6955, 2019}


13. H. L. Tae, S. J. Bong, K. J. Min, G. P. Chan, C. Jun-Ho, and D. H. Park, Sci. Rep. 6, 35446 (2016)

14. P. L. Tran, E. Huynh, A. N. Hamood, A. de Souza, D. Mehta, K. W. Moeller, C. D. Moeller, M. Morgan, and T. W. Reid, J. Wound Care 26, 16 (2017).

15. R. Murugan, Z. M. Huang, F. Yang, and S. Ramakrishna, J. Nanosci. Nanotech. 7, 4595 (2007).

16. A. Seidi, K. Sampathkumar, A. Srivastava, S. Ramakrishna, and M. Ramalingam, J. Nanosci. Nanotech. 13, 4647 (2013).

17. S. Liao, S. Ramakrishna, and M. Ramalingam, J. Biomater. Tissue Eng. 1, 111 (2011).

18. R. Murugan and S. Ramakrishna, Tissue Eng. 12, 435 (2006).

19. M.-N. Labour, M. Walsh, M. Cavaignac, K. Eichholz, E. deBarra, and D. A. Hoey, J. Biomater. Tissue Eng. 8, 206 (2018).

20. A Seidi and M. Ramalingam, J. Biomater. Tissue Eng. 2, 89 (2012).
21. R. Balu, T. S. Kumar, M. Ramalingam, and S. Ramakrishna, J. Biomater. Tissue Eng. 1, 30 (2011).

22. S. K. Bhullar, D. Rana, Huseyin Lekesiz, Ayse Celik Bedeloglu, J. Ko, Y. Cho, Z. Aytac, T. Uyar, M. Jun, and Murugan Ramalingam, Mater. Sci. Eng. C 81, 334 (2017).

23. Murugan Ramalingam, M. F. Young, V. Thomas, L. Sun, L. C. Chow, C. K. Tison, K. Chatterjee, W. C Miles, and C. G. Simon Jr., J. Biomater. Appl. 27, 695 (2013).

24. E. Tamara, E. Mohamad Nasser, D. Christelle, B. Sophie, and D. Philippe, J. Colloid Inter. Sci. 273, 381 (2004).

25. L. Li, L. Yu, L. Hao, and F. Yuee, Eur. Polym. J. 40, 2739 (2004).

26. Y. Yuehua and L. T. Randall, Contact angle and wetting properties, Surface Science Techniques, edited by G. Bracco and B. Holst, Springer-Verlag, Heidelberg, Germany (2013), Vol. 51, p. 3.

Received: 10 September 2018. Accepted: 3 October 2018. 